\title{
Synthesis and local structure of doped nanocrystalline zinc oxides
}

\author{
Joachim U. Brehm ${ }^{\text {a) }}$ \\ Joint Research Laboratory Nanomaterials, Technical University Darmstadt \\ and Forschungszentrum Karlsruhe, Petersenstrasse 23, 64287 Darmstadt, Germany \\ Markus Winterer \\ Institute of Combustion and Gasdynamics, University Duisburg-Essen, Lotharstrasse 1, \\ 47057 Duisburg, Germany \\ Horst Hahn \\ Joint Research Laboratory Nanomaterials, Technical University Darmstadt \\ and Forschungszentrum Karlsruhe, Petersenstrasse 23, 64287 Darmstadt, Germany
}

(Received 28 February 2006; accepted 22 June 2006; published online 25 September 2006)

\begin{abstract}
Nanocrystalline zinc oxides are produced by chemical vapor synthesis and characterized by x-ray diffraction, high resolution transmission electron microscopy, nitrogen sorption, and extended $\mathrm{x}$-ray absorption fine structure. Dopant elements (aluminum, gallium, and indium) influence the particle size of the powders as well as lattice parameters and local structure. The different effects of the three dopant elements are characterized. (c) 2006 American Institute of Physics.

[DOI: 10.1063/1.2349430]
\end{abstract}

\section{INTRODUCTION}

Semiconducting transparent thin films of oxide materials have been known since the discovery of conducting cadmium oxide by Badeker in 1907. ${ }^{1}$ About 50 years later with the deposition of tin-doped indium oxide (known as ITO or indium-tin oxide) films the class of transparent conducting oxides (TCOs) was coined. These materials mostly find applications as thin films, for example, in flat panel displays, low-emissivity windows, solar cells, transparent heating elements in windscreens, gas sensors, and antistatic coatings. TCO films are commonly prepared by physical- or chemicalvapor-deposition-type processes with their well known advantages. An overview on the preparation and applications of TCOs can be found in Ref. 2. Most of these preparation techniques require high substrate temperatures. Alternative methods of applying a film are required for substrate materials with low melting points such as polymers. Therefore, nanocrystalline dispersible particles are of interest. Today ITO is the most commonly used material in industrial applications. Because of the rare abundance and consequently high price of indium in nature, materials with similar properties and higher availability are sought after.

One promising replacement material is doped zinc oxide. In the production of solar cells it has already replaced ITO due to its higher resistance to deterioration in plasma involving processes. We produced group-III-doped $\mathrm{ZnO}$ by chemical vapor synthesis ${ }^{3}$ (CVS) at atmospheric pressures. The position of dopants in the host lattice is of major importance for properties such as conductivity. ${ }^{4}$ In order to understand the influence of dopants on structure and properties, the samples were characterized by x-ray diffraction, high resolution transmission electron microscopy, nitrogen sorption, and extended x-ray absorption fine stucture (EXAFS). Up to now EXAFS investigations of $\mathrm{ZnO}$ mainly concern topics of

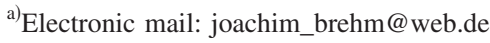

structural development in pure $\mathrm{ZnO}$ (Refs. 5-7 or the use of $\mathrm{Cu}$-doped $\mathrm{ZnO}$ for catalysis of methanol synthesis. ${ }^{8-10}$ Only two investigations exist on In-doped $\mathrm{ZnO}$ analyzed by EXAFS. ${ }^{11,12}$

\section{EXPERIMENTAL METHODOLOGY}

Nanocrystalline zinc oxide was synthesized using zinctetramethyl-heptanedionate $\left(\mathrm{Zn}-(\mathrm{thd})_{2}\right)$ as solid precursor (Epichem Oxides \& Nitrides, Mildenhall, U.K.) and aluminum-, gallium-, and indium-tetramethyl-heptanedionate for doping. Figure 1 shows a schematic drawing of the experimental setup of the reactor. Helium [400 SCCM (SCCM denotes cubic centimeter per minute at STP)] is used to transport the precursor vapor to the reaction zone, and oxygen $(5000 \mathrm{SCCM})$ is added well behind the precursor container to prevent preliminary oxidation and/or combustion. The precursor vapor is transported into the hot wall reactor where it decomposes and reacts to oxide particles which grow by collision and sintering to nanometer sized particles. These are transported by the gas stream to the particle collector, where they are separated from the gas stream by thermophoresis through a thermal gradient between infrared lamps and the water cooled walls. Furnace temperatures of $1000{ }^{\circ} \mathrm{C}$ and atmospheric pressure were used as process parameters with resulting residence times in the hot zone of about $0.3 \mathrm{~s}$.

Characterization of the powders was performed using a nitrogen sorption instrument Autosorb 3B (Quantachrome) to determine the specific surface area. The powders were heated to $200{ }^{\circ} \mathrm{C}$ under vacuum before the sorption measurements to remove adsorbed molecules from the sample surface. Transmission electron microscopy by a CM20 Ultra Twin (Philips) was employed to determine crystallinity and grain size distribution. Crystalline phases, crystallite sizes, and lattice parameters were determined by $\mathrm{x}$-ray diffraction (XRD) at room temperature using an $\mathrm{x}$-ray diffractometer D-5000 


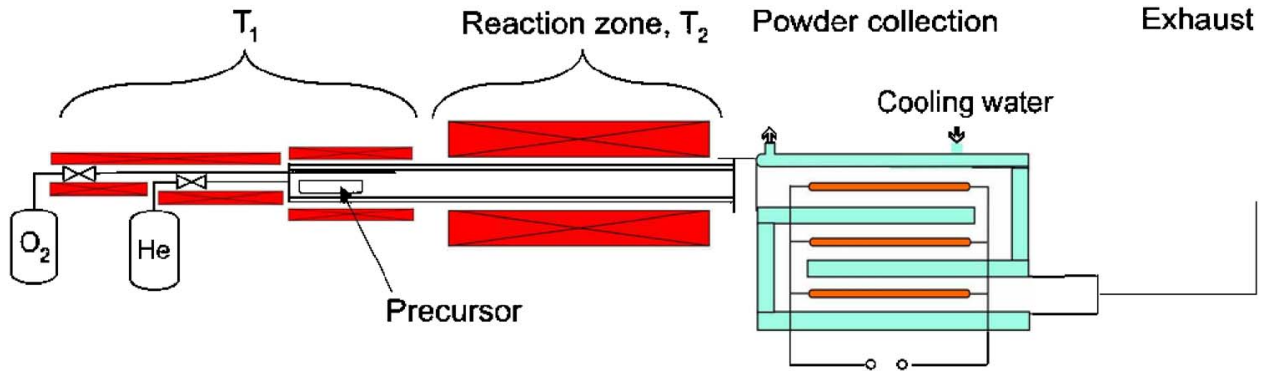

FIG. 1. (Color online) Experimental setup of the CVS system for the production of nanocrystalline $\mathrm{ZnO}$ and doped $\mathrm{ZnO} \quad\left(T_{1}\right.$ was about $200-220{ }^{\circ} \mathrm{C}$ and $T_{2} 1000{ }^{\circ} \mathrm{C}$ ).

(Siemens). Primary particle sizes (corresponding to coherent diffracting domains) were calculated from the line broadening using Rietveld refinements by FULLPROF (Ref. 13) of $\mathrm{Cu} K \alpha \mathrm{XRD}$ patterns. The local structure was determined by EXAFS measured at Zn $K$ edge $(9659 \mathrm{eV})$, In $K$ edge $(27940 \mathrm{eV})$, and $\mathrm{Ga} K$ edge $(10367 \mathrm{eV})$ in transmission at HASYLAB (DESY, Hamburg) beamlines A1 and X1 at room temperature. EXAFS data were measured up to $1000 \mathrm{eV}$ above the $K$-edge energies except for samples doped with $\mathrm{Ga}$ due to overlap of the $\mathrm{Zn}-K$-edge data with those of the $\mathrm{Ga} K$ edge. For sample preparation appropriate amounts of the nanocrystalline powders were mixed in a mortar with polyethylene (spectrophotometric grade, Aldrich) and then uniaxially pressed at $250 \mathrm{MPa}$ pressure to yield pellets of $12 \mathrm{~mm}$ diameter and approximately $0.7 \mathrm{~mm}$ thickness. The dopant- $K$-edge measurements were repeated four times to improve the signal-to-noise ratio since the content of dopants was low. After extracting the data for the $\mathrm{Zn}-K$-edge measurement, the dopant- $K$-edge measurements were averaged and then the EXAFS data were also extracted. The dopant content was determined by analysis of the absorption coefficient. The results agree with the nominally intended dopant content for $\mathrm{Ga}$ and In doping (see Table I); for Al doping no data are available.

\section{DATA ANALYSIS}

In Rietveld refinements of powder diffraction patterns the complete diffractogram is fitted by a nonlinear least- squares method using a structure factor computed from the appropriate space group and coordinates of the asymmetric unit. XRD Rietveld refinements were performed with FULLPROF using initial values for the wurtzite $\mathrm{ZnO}$ structure (space group 186, $\mathrm{Pb}_{3} \mathrm{mc}$ ) published by Albertson et al. ${ }^{14}$ Analysis of the isotropic microstrain and grain size broadening is possible using a Thompson-Cox-Hastings-pseudoVoigt line shape function. Errors were estimated using standard FULLPROF procedures. The background was refined using a polynomial function.

The EXAFS signal $\chi_{i}(k)$ of the absorbing atom type $i$ can be computed by a product integral of the partial pair distribution functions of all scattering atoms $j$ with the EXAFS signal corresponding to a single pair of atoms $\gamma_{i j}(r, k)$ if only single scattering contributions are considered:

$$
\chi_{i}(k)=\sum_{j} \int_{0}^{\infty} 4 \pi r^{2} \rho \gamma_{i j}(r, k) g_{i j}(r) d r,
$$

where $r$ is the distance from atom $i$ and $\rho$ is the number density of the sample. The EXAFS signal of an atom pair $\gamma_{i j}(r, k)$ is amplitude $\left[A_{i j}(k, r)\right]$ and phase $\left[\Phi_{i j}(k, r)\right]$ modulated:

$$
\gamma_{i j}(r, k)=A_{i j}(k, r) \sin \left[2 k r+\Phi_{i j}(k, r)\right] .
$$

In order to eliminate multiple scattering observed for wurtzite-type structures, the data were filtered using a range up to $4 \AA$ of the Fourier transform (FT) EXAFS spectra. Subsequently they were analyzed by a reverse Monte Carlo

\begin{tabular}{|c|c|c|c|c|c|c|c|c|c|}
\hline & \multicolumn{9}{|c|}{ Sample } \\
\hline & \multicolumn{3}{|c|}{$\mathrm{ZnO}$} & \multicolumn{3}{|c|}{$\mathrm{ZnO}: \operatorname{In} 5 \%$} & \multicolumn{3}{|c|}{$\mathrm{ZnO}: \mathrm{Al} 5 \%$} \\
\hline Z & & 2 & & & 2 & & & 2 & \\
\hline$a, b(\AA)$ & & $3.2516(2)$ & & & $3.2581(5)$ & & & $3.256(2)$ & \\
\hline$c(\AA)$ & & $5.2096(4)$ & & & $5.2123(9)$ & & & $5.197(2)$ & \\
\hline \multirow[t]{2}{*}{$V\left(\AA^{3}\right)$} & & $47.69(4)$ & & & $47.9(2)$ & & & $47.7(3)$ & \\
\hline & $x$ & $y$ & $z$ & $x$ & $y$ & $z$ & $x$ & $y$ & $z$ \\
\hline Zn (dopant) & 0.333 & 0.666 & 0.000 & 0.333 & 0.666 & 0.000 & 0.333 & 0.666 & 0.000 \\
\hline $\mathrm{O}$ & 0.333 & 0.666 & $0.38(2)$ & 0.333 & 0.666 & $0.39(2)$ & 0.333 & 0.666 & $0.40(5)$ \\
\hline$X$ & & $0.16(4)$ & & & $0.68(11)$ & & & $1.24(36)$ & \\
\hline$Y$ & & $0.255(1)$ & & & $0.377(5)$ & & & $0.503(6)$ & \\
\hline$R_{B}(\%)$ & & 1.64 & & & 2.82 & & & 3.84 & \\
\hline$R_{\mathrm{wp}}(\%)$ & & 9.37 & & & 8.48 & & & 13.60 & \\
\hline
\end{tabular}

TABLE I. Showcase results of Rietveld refinements used as input for RMCXAS simulations. 
TABLE II. Results of BET and XRD size determination (varying values due to sample variations, e.g., doping concentration) for different CVS nanocrystalline $\mathrm{ZnO}$ samples.

\begin{tabular}{|c|c|c|c|c|}
\hline \multirow[b]{2}{*}{$\begin{array}{l}\text { Sample } \\
\text { (intended } \\
\text { doping) }\end{array}$} & \multicolumn{4}{|c|}{ Method } \\
\hline & $\begin{array}{c}\text { BET } \\
\text { Surface area } \\
\left(\mathrm{m}^{2} / \mathrm{g}\right)\end{array}$ & $\begin{array}{c}\text { BET } \\
\text { Particle size } \\
(\mathrm{nm})\end{array}$ & $\begin{array}{c}\text { XRD } \\
\text { Grain size } \\
(\mathrm{nm})\end{array}$ & $\begin{array}{c}\text { Dopant content } \\
\text { (at. \%) }\end{array}$ \\
\hline $\mathrm{ZnO}$ & 39 & $27.5(3)$ & $25.2(4)$ & \\
\hline $\mathrm{ZnO}: \mathrm{In} 1 \%$ & 33 & $32.5(3)$ & $21.2(4)$ & \\
\hline $\mathrm{ZnO}: \mathrm{In} 5 \%$ & 39 & $27.4(3)$ & $14.9(3)$ & $4.8(8)$ \\
\hline $\mathrm{ZnO}: \mathrm{Ga} 2 \%$ & 36 & $30.0(3)$ & $19.3(4)$ & $2.1(3)$ \\
\hline $\mathrm{ZnO}: \mathrm{Ga} 3 \%$ & 34 & $31.8(3)$ & $17.8(4)$ & $2.8(4)$ \\
\hline $\mathrm{ZnO}: \mathrm{Al} 2 \%$ & & & $13.3(6)$ & \\
\hline $\mathrm{ZnO}: \mathrm{Al} 5 \%$ & 56 & $19.0(2)$ & $11.1(4)$ & \\
\hline
\end{tabular}

(RMC) based method by the RMCXAS program in $k$ space as described in Ref. 15. The amplitude and phase functions for this configuration were calculated using FEFF8 (Ref. 16) neglecting multiple scattering by only calculating second order distribution functions. The RMCXAS program was run with configurations of 784 atoms (containing appropriate amounts of dopant atoms) and appropriate hard-sphere potentials for the different models. The size of the box of atoms was four times the lattice constant $c$ and seven times the $a$ and $b$ lattice constants using lattice parameters obtained by $\mathrm{Ri}$ etveld refinement of XRD data (see Table II). A constant error of $\sigma_{i}=0.003$ representing the "temperature" was used for all RMC fits. After a sufficient number of cycles (typically the number of cycles equals the number of atoms) convergence was obtained.

With RMCXAS two spectra with the structural information from two different $\mathrm{x}$-ray absorbing elements in the sample can be fitted simultaneously with one mutual model. The deviation between the fitted model and the measurement is indicated by the so called $R$ value and is given in percent. It is possible to extract partial pair distribution functions for $\mathrm{Zn}-\mathrm{Zn}$ and $\mathrm{Zn}-\mathrm{O}$ from a single $\mathrm{Zn}-K$-edge spectra because the EXAFS signal depends on the backscattering atoms by phase and amplitude functions. The partial pair distribution functions obtained by RMC were analyzed by a moment analysis to yield coordination numbers, coordination distances, second moments, and corresponding errors.

\section{RESULTS AND DISCUSSION}

\section{A. Powder characterization}

A typical transmission electron microscopy (TEM) micrograph (Fig. 2) of an In-doped $\mathrm{ZnO}$ sample shows that the crystallinity of the samples is very good. The lattice fringes extend across the total grain diameter up to the particle edges. This is due to the high synthesis temperatures. In this temperature regime solid state and surface diffusion are facilitated and defects can anneal during synthesis. The geometric mean deviation of the size distribution was in the range of 1.2-1.4. The morphology of the powders was mostly spherical with some grains showing hexagonal facets. No separate phases for doped samples can be observed by

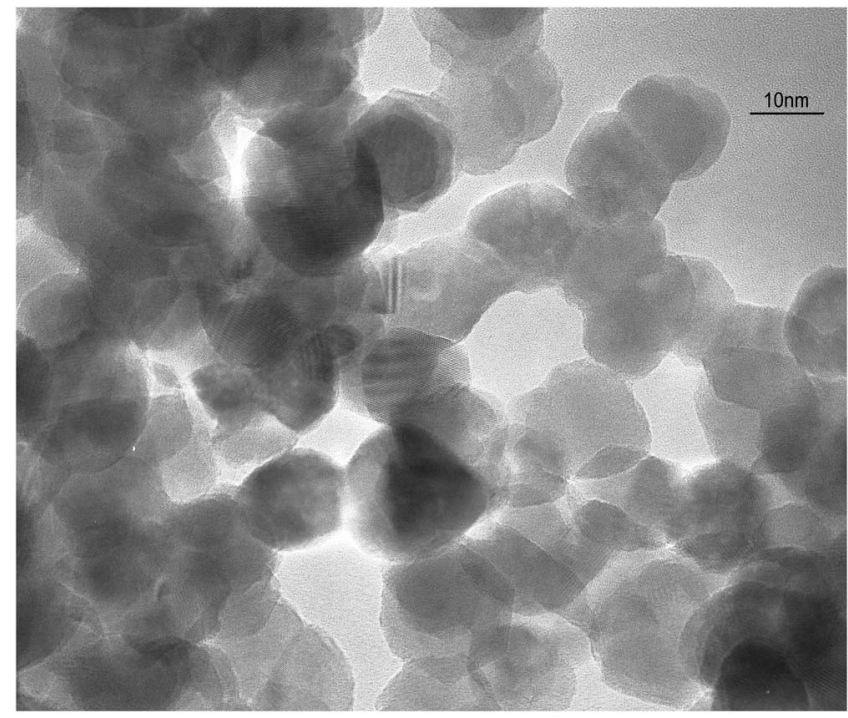

FIG. 2. TEM image of In-doped $\mathrm{ZnO}$.

electron diffraction. This is consistent with the low background between the Bragg reflections observed in XRD patterns. Sintering necks are rarely observed at the particle contacts. Measurements by nitrogen sorption revealed high surface areas of $32-56 \mathrm{~m}^{2} / \mathrm{g}$ for the powders produced by atmospheric pressure CVS (see Table II). Average particle sizes were calculated from the specific surface area assuming
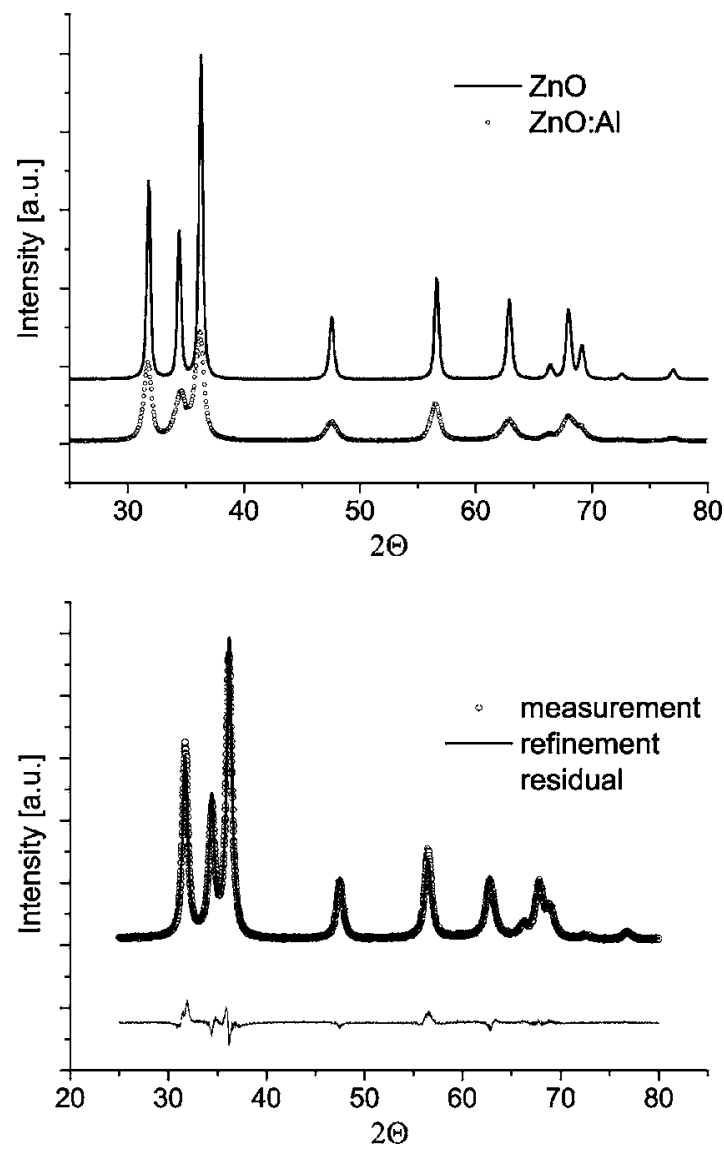

FIG. 3. X-ray diffractograms of the synthesized powders (top, comparison of Al-doped and undoped $\mathrm{ZnO}$; bottom, Rietveld refinement of In-doped $\mathrm{ZnO})$. 
TABLE III. Ionic radii for different coordinations of the cations in the different samples (Ref. 28).

\begin{tabular}{ccc}
\hline \hline Cation type & $\begin{array}{c}\text { Radius (pm) } \\
\text { (four fold } \\
\text { coordination) }\end{array}$ & $\begin{array}{c}\text { Radius }(\mathrm{pm}) \\
\text { (Six fold } \\
\text { coordination) }\end{array}$ \\
\hline $\mathrm{Zn}\left(2^{+}\right)$ & 74 & 88 \\
$\mathrm{Al}\left(3^{+}\right)$ & 53 & 68 \\
$\mathrm{Ga}\left(3^{+}\right)$ & 61 & 76 \\
$\mathrm{In}\left(3^{+}\right)$ & 76 & 94 \\
\hline \hline
\end{tabular}

separate, monodisperse, spherical particles. The grain size varies depending on the choice and amount of doping element from 10 to $25 \mathrm{~nm}$ (compare Fig. 3). Values of the isotropic particle size broadening are listed in Table II. The deviations between particle sizes determined from the specific surface area and the grain sizes determined by XRD are most probably due to the assumption of spherical particles and a small amount of agglomeration in the powders. The deviations between particle size and grain size are small for the pure $\mathrm{ZnO}$ samples. However, for the doped powders the grain size is considerably smaller compared to the particle size. This can be explained by a reduction of the sintering rate due to incorporation of the group III atoms into the $\mathrm{ZnO}$ lattice in the CVS process. In agreement with this explanation is the observation that the grain size is decreasing with increasing deviation of the dopant cationic radii from the ionic radius of zinc, implying different solid state diffusion coefficients. The CVS process consists of several parts: conversion of the precursor into monomers, formation of clusters from monomers, coagulation of clusters and formation of agglomerates, sintering of the primary particles within the agglomerates, and heat exchange with the reactor. ${ }^{17}$

\section{B. Crystal structure: Lattice parameters}

XRD patterns of the powder samples show only reflections of pure hexagonal wurtzite structure (space group: $P 63 m c$ ) for all $\mathrm{ZnO}$ samples prepared (see Rietveld refinement for $\mathrm{ZnO}$ :In in Fig. 3). The ionic radii for the possible four- or sixfold coordination for the cations are shown in

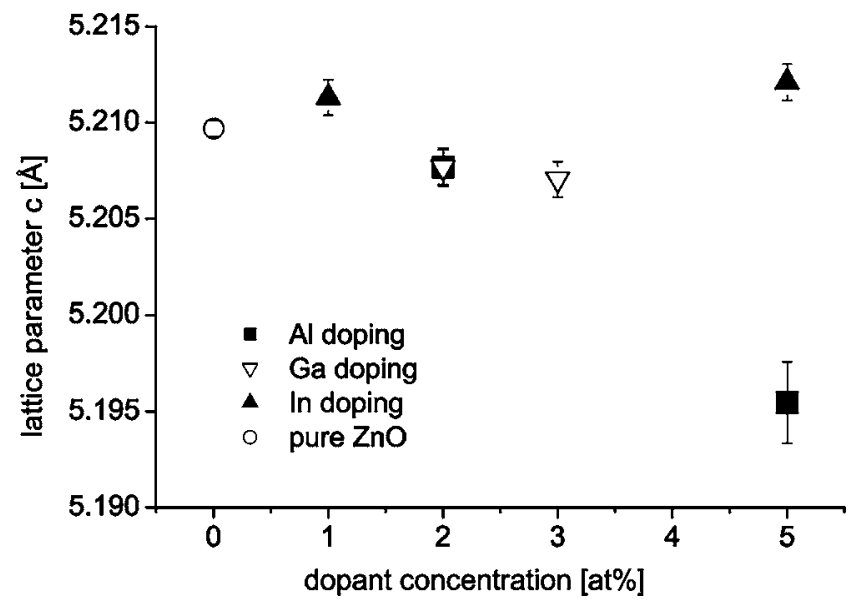

FIG. 4. Lattice parameter $c$ as a function of dopant concentration from Rietveld refinements.

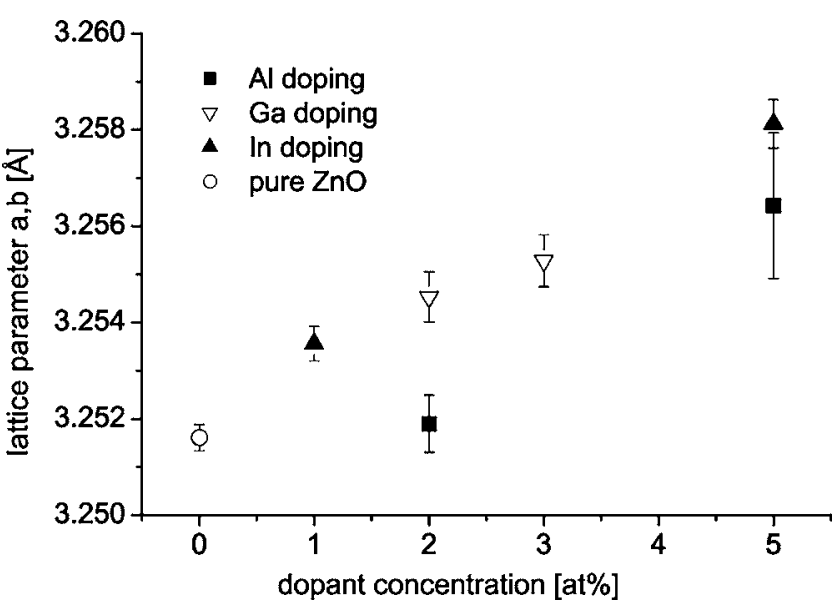

FIG. 5. Lattice parameters $a$ and $b$ as a function of dopant concentration from Rietveld refinements.

Table III. Upon doping the lattice constants of the wurtzite structure change. The lattice parameter $c$ decreases for dopant atoms with smaller ionic radii ( $\mathrm{Al}$ and $\mathrm{Ga}$ ) and increases with larger ionic radii (In) compared to $\mathrm{Zn}$ on which site the dopants are assumed to reside. The behavior of these changes can be seen in Fig. 4. The Ga- and In-doped samples show an approximately linear change with concentration. A deviation from this is observed for the sample doped with 2 at. \% $\mathrm{Al}$ since it does not show a smaller value compared to the 2 at. \% Ga-doped sample.

The following effects are found for the $a$ and $b$ lattice constants of the hexagonal plane: substitution by the larger In atoms increases lattice parameters $a$ and $b$ due to the larger ionic radius in agreement with the linear Vegard's law. For $\mathrm{Al}$ and $\mathrm{Ga}$ a surprising behavior is observed. Both ions are smaller than $\mathrm{Zn}$, yet larger values for $a$ and $b$ are found, which cannot be explained geometrically by atoms of $\mathrm{Al}$ and $\mathrm{Ga}$ residing on $\mathrm{Zn}$ lattice sites (Fig. 5). Again Ga doping shows a linear behavior with increasing dopant level whereas for $\mathrm{Al}$ a nonlinear behavior is observed. The unit cell volume can be calculated from the lattice parameters. Surprisingly, for all samples the unit cell volume also increases with increasing dopant content (Fig. 6). The increase of the unit cell volume correlates with the ionic radii: for In the effect is

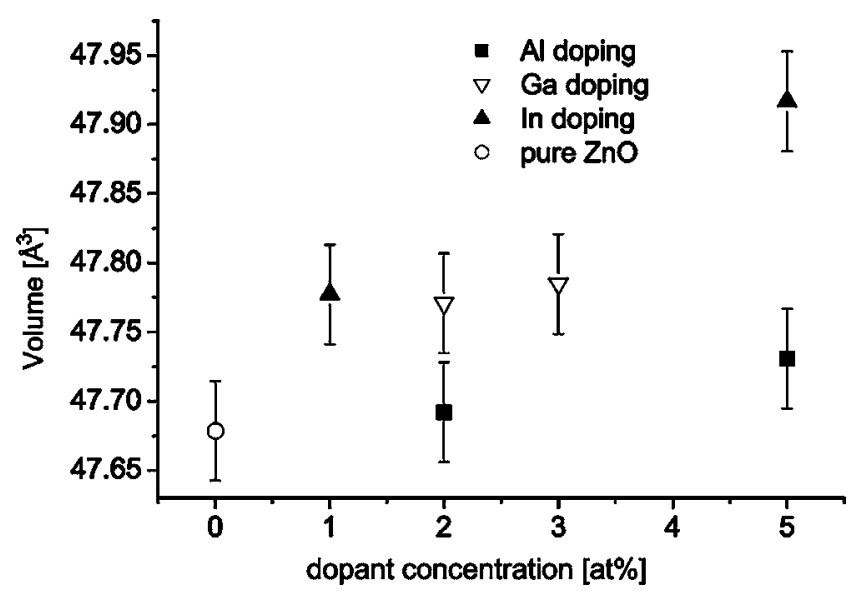

FIG. 6. Lattice volume as a function of dopant concentration from Rietveld refinements. 


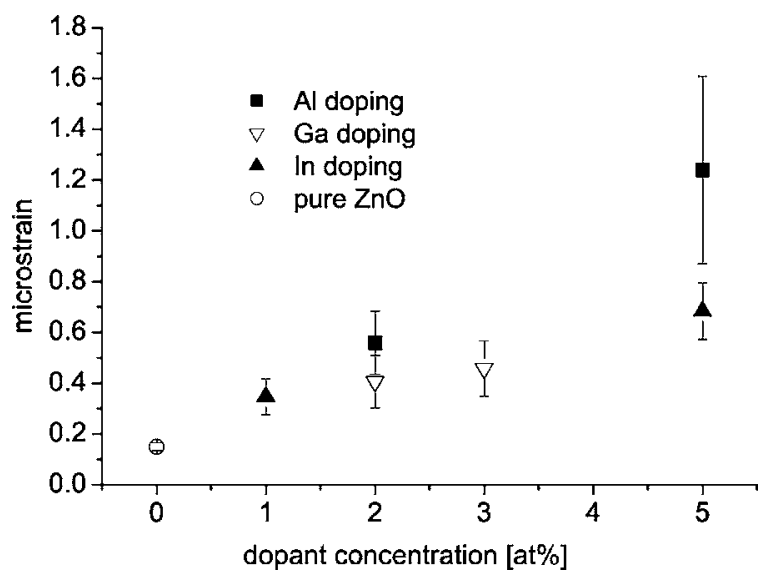

FIG. 7. Microstrain depending as a function of dopant concentration from Rietveld refinements.

largest, while for Al the effect is smallest. The microstrain obtained from the Rietveld refinement increases linearly with dopant concentration and is largest for Al (Fig. 7), correlating to the highest difference in ionic radius between dopant and zinc ions. So the effects on the cell structure are influenced by the differences of ionic radii of the dopants and their concentration.

The changes in lattice parameters cannot be sufficiently understood by taking only ionic radii into account. Another possible explanation is the general change of lattice parameters in covalent systems with decreasing grain size. It has been shown ${ }^{18,19}$ that in nanocrystalline systems a relaxation of lattice parameters due to a decrease of the integral attractive forces in the crystal occurs. This can explain the observation of increasing $a$ and $b$ lattice parameters independent of the type of dopant. Considering a softer bond between $\mathrm{Zn}$ and $\mathrm{O}$ in the $c$ direction (see the next section), it is clear that this lattice parameter is much more sensitive on the type of dopant element. The higher charge density of the dopant elements of group III compared to $\mathrm{Zn}^{2+}$ leads to high attractive forces between substitutional dopant atoms and oxygen neighbors along the $c$ axis. Therefore, the $c$ parameter shows a strong dependence on dopant element size and charge density.

\section{Crystal structure: Parameter $u$ and bond length}

In the $\mathrm{ZnO}$ wurtzite structure zinc atoms occupy the special position $1 / 3,2 / 3,0$ and oxygen occupies the special position $1 / 3,2 / 3, u$. Therefore, $u$ can be interpreted as the relative shift of the anionic sublattice to the cationic sublattice in $z$ direction. In the literature ${ }^{7,8}$ values for $u$ of $0.3817-$ 0.3819 are found. Kisi and Elcombe ${ }^{20}$ present a correlation $u(c / a)=\sqrt{3 / 8}$ for $u$ with the lattice parameter ratio $c / a$ derived from geometrical considerations on the basis of a hexagonal close packing. They present values of own measurements and literature values of differently prepared $\mathrm{ZnS}$ and $\mathrm{ZnO}$ samples. In Fig. 8 the straight line represents this correlation. The data points represent the results of the differently doped and also the pure nanocrystalline $\mathrm{ZnO}$ investigated here. The decrease of $c / a$ with larger $u$ is much less pronounced for our samples compared to Kisi and Elcombe's

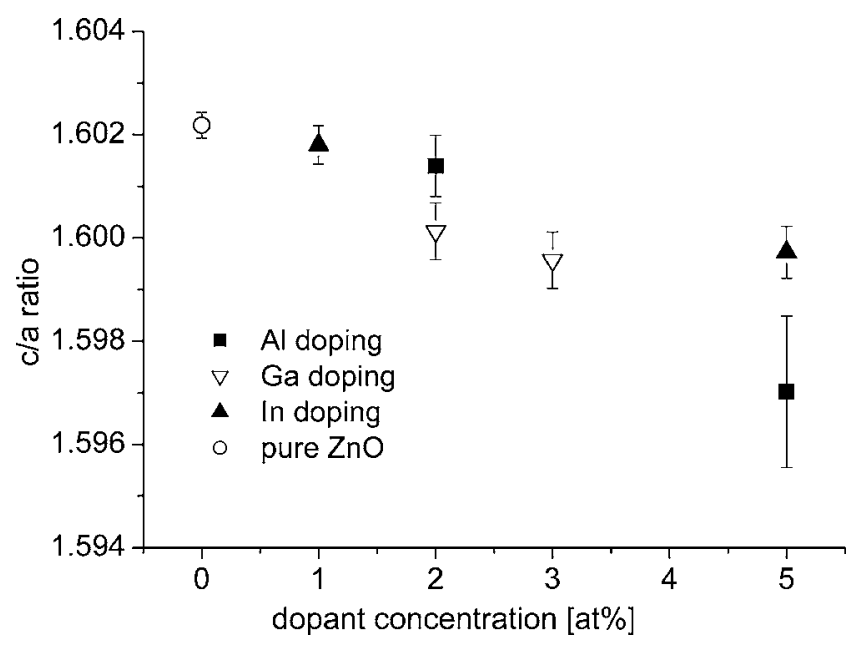

FIG. 8. Ratio of lattice parameters $c / a$ as a function of position parameter $u$ compared to the relation found by Kisi and Elcombe. The error bars are smaller than the symbol size.

results. Similar results have been published ${ }^{21}$ for one sample of nanocrystalline $\mathrm{ZnO}$ indicating a dependence of the $c / a$ $-u$ correlation on the reactants used in the used wet chemical synthesis. The ratio $c / a$ as a function of dopant concentration (Fig. 9) decreases generally with increasing dopant content.

The decrease of $c / a$ has also been observed in structural investigations of the wurtzite to rocksalt transformation in high-pressure experiments. ${ }^{22}$ Therefore, the behavior in our samples may be interpreted by an internal pressure induced by the dopants. An alternative explanation for this behavior can also be internal strain as observed by the general increase in microstrain with increasing dopant content in the Rietveld results.

From the values of $u$ further insight into the structure can be obtained. Only in an ideal wurtzite crystal structure with $c / a=1.6333$ and $u=3 / 8$ all $\mathrm{Zn}-\mathrm{O}$ bond lengths are identical. For deviations in $c / a$ and $u$ the $\mathrm{Zn}-\mathrm{O}$ bond in the $c$-axis direction is different in comparison with the other $\mathrm{Zn}-\mathrm{O}$ bond lengths. The bond length in the $c$ direction can simply be calculated by $u c$ and the other three by $\left[a^{2} / 3+(1 / 2\right.$ $\left.-u)^{2} c^{2}\right]^{1 / 2}$ (Table IV). The bond lengths parallel to the $a, b$

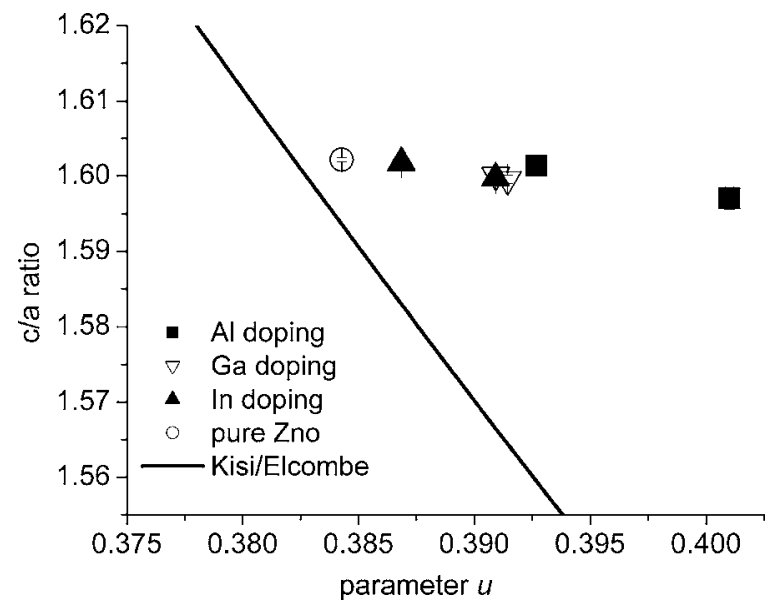

FIG. 9. $c / a$ ratio as a function of doping level. 
TABLE IV. Bond length for $\mathrm{Zn}-\mathrm{O}$ determined from Rietveld refined parameters.

\begin{tabular}{lcc}
\hline \hline Sample & $\begin{array}{c}\text { Distances } \perp c \\
r(\AA)\end{array}$ & $\begin{array}{c}\text { Distance } \| c \\
r(\AA)\end{array}$ \\
\hline Ideal wurtzite & 1.98 & 1.98 \\
ZnO & $1.97(2)$ & $2.00(2)$ \\
ZnO:Al 5\% & $1.95(2)$ & $2.08(2)$ \\
ZnO:Ga 3\% & $1.96(2)$ & $2.04(2)$ \\
ZnO:In 5\% & $1.97(2)$ & $2.04(2)$ \\
\hline
\end{tabular}

plane remain nearly constant, whereas the $\mathrm{Zn}-\mathrm{O}$ distance along the $c$ axis increases according to the $u c$ dependence. With decreasing values of $c$ this can be interpreted by an internal pressure or higher strain in the particle. In highpressure experiments similar behaviors for bond lengths and lattice parameters have been observed.

\section{Local structure and dopant sites by extended x-ray absorption fine structure (EXAFS)}

XRD provides only information averaged over the entire sampled volume on the basis of the long range order (periodic structure). As details of the local structure cannot be obtained by XRD, EXAFS was used to investigate whether the dopants are substitutional on $\mathrm{Zn}$ sites or reside on interstitial sites in the wurtzite crystal structure or form a second phase. $\mathrm{Zn}-K$-edge and In- $K$-edge EXAFS spectra of $\mathrm{ZnO}$ doped with 5 at. \% In were analyzed using RMCXAS with a single model (Fig. 10 and 11). The $R$ values were $14 \%$ and $22 \%$ for $\mathrm{Zn} K$ edge and In $K$ edge, respectively. The residuals in the optical Fourier transforms on both spectra have similar origin. The deviations at low radii are due to insufficient background subtraction. The deviation at about $4 \AA$ arises from the cutoff in the pair distribution functions used to accommodate the Fourier filtering range in the RMC model. The remaining differences are probably due to multiple scattering.

The resulting partial pair distribution functions are shown in Fig. 12. They are normalized to the relative content of the absorbing element concentration in the samples. Therefore, In-O and $\mathrm{Zn}-\mathrm{O}$ exhibit similar areas of the peaks. The In-In pair distribution is noisy due to the low In content. The average In-In distances are identical to the $\mathrm{Zn}-\mathrm{Zn}$ distances. This is consistent with In substituting $\mathrm{Zn}$ since the distances of $\mathrm{Zn}$ to an interstitial cation would be much smaller as can be seen later. The In-O distances are shifted to higher values in comparison with $\mathrm{Zn}-\mathrm{O}$ distances, reflecting the larger ionic radius of In. This information is not accessible from Rietveld analysis of XRD data as a periodic model is used. In Rietveld analysis this phenomenon can give rise to the observed behavior of microstrain. Coordination numbers, coordination distances, and second moments (corresponding to Debye-Waller factors) are displayed in Table V. It can be clearly seen that In has the same oxygen coordination number of 4 as $\mathrm{Zn}$ in contrast to pure $\mathrm{In}_{2} \mathrm{O}_{3}$ where the coordination number is 6 . The In-O bond $(2.08 \AA)$ is longer compared to the $\mathrm{Zn}-\mathrm{O}$ bond length $(1.98 \AA)$ due to the larger ionic radius of $\mathrm{In}$. In pure bixbyite-type $\mathrm{In}_{2} \mathrm{O}_{3}$ it is
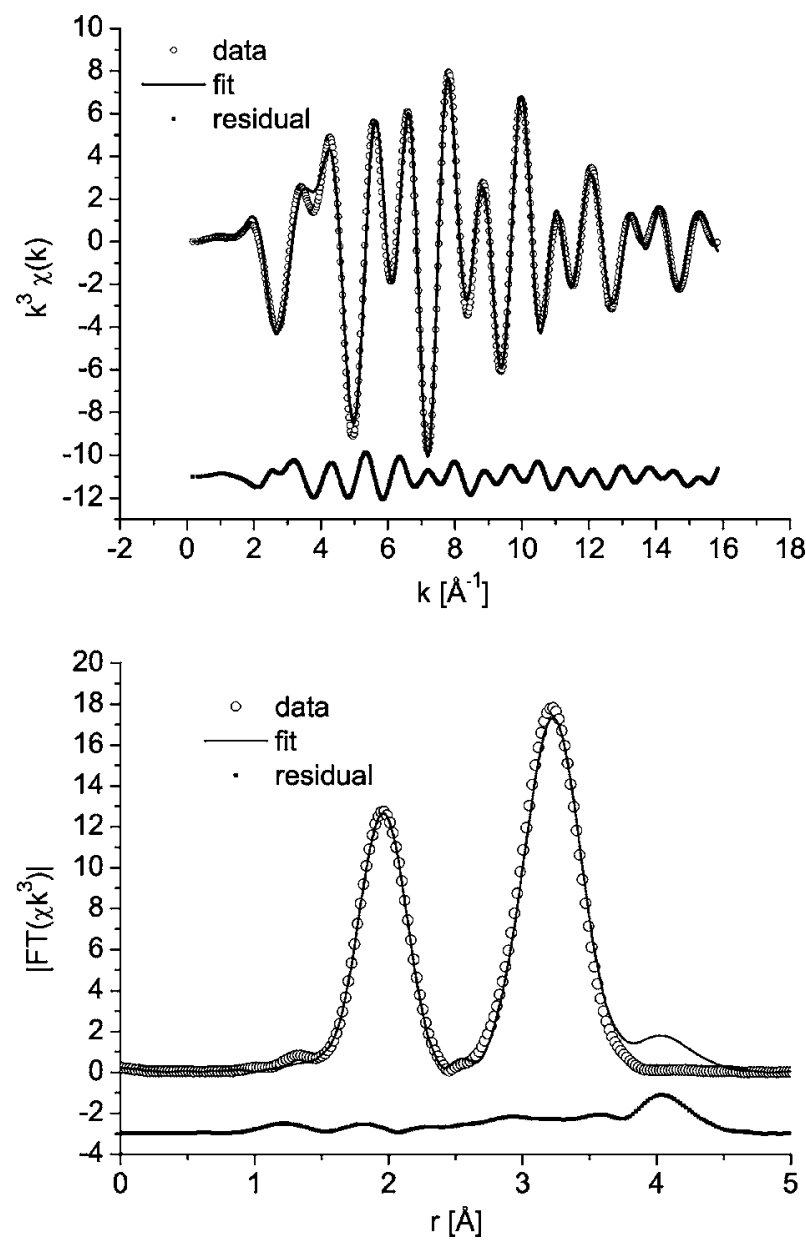

FIG. 10. RMC analysis of EXAFS spectra of In-doped (5 at. \%) ZnO: Zn $K$ edge on the top and optical Fourier transform on the bottom.

even longer with $2.17 \AA .{ }^{11}$ These results agree with values for valence bonds computed from the bond lengths of In-O using the program BOND VALENCE CALCULATOR. ${ }^{23}$ Values of 0.586 for In-O in our samples and 0.472 for In-O in pure $\mathrm{In}_{2} \mathrm{O}_{3}$ were obtained. These results reflect the stronger In-O binding due to less oxygen atoms available in comparison with the parent oxide and a higher charge density at In compared to $\mathrm{Zn}$ (note that bond valence values for $\mathrm{Zn}-\mathrm{O}$ are also 0.472). For higher In contents the results in Ref. 11 show a sixfold coordination. For In contents comparable to our samples in Ref. 12 the same In-O distance and fourfold coordination were found. However, the error in coordination numbers from our analysis is smaller and, therefore, a coordination number of 6 can be excluded, in contrast to Ref. 12 . Furthermore, the 12-fold Zn-cation next nearest neighbor coordination remains intact because the additional $\mathrm{Zn}$-In contribution is included.

An extension of Vegard's law is the virtual crystal approximation (VCA). This theorem states that a linear change of the lattice parameter with dopant concentration results in a linear variation of the interatomic distances. The behavior of the cation-anion distance according to EXAFS for our samples is shown in Fig. 13. The VCA-like behavior is shown as a straight line calculated from Rietveld results. The $\mathrm{Zn}-\mathrm{O}$ distances follow the VCA within the errors; nevertheless a behavior as presented in Ref. 24 with a dependence of 

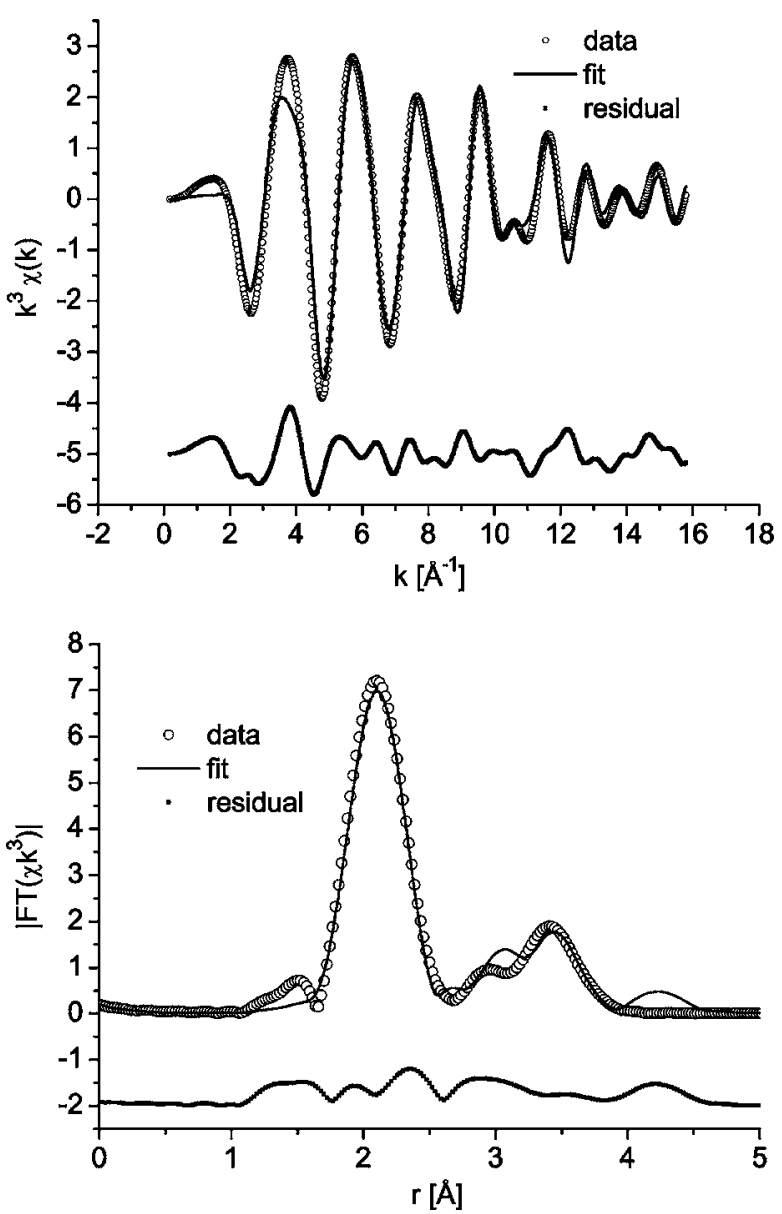

FIG. 11. RMC analysis of EXAFS spectra of In-doped (5 at. \%) ZnO: In $K$ edge on the top and optical Fourier transform on the bottom.

interatomic distances smaller than predicted by the VCA as a function of the composition seems possible. The In-O distances are definitely not following the VCA, showing a much larger distance at 5 at. \% In than expected. Obviously, the In-O distances depend little on the composition in contrast to the VCA prediction. For the $\mathrm{Zn}-\mathrm{Zn}$ distances a similar behavior as for $\mathrm{Zn}-\mathrm{O}$ can be observed; however, a behavior

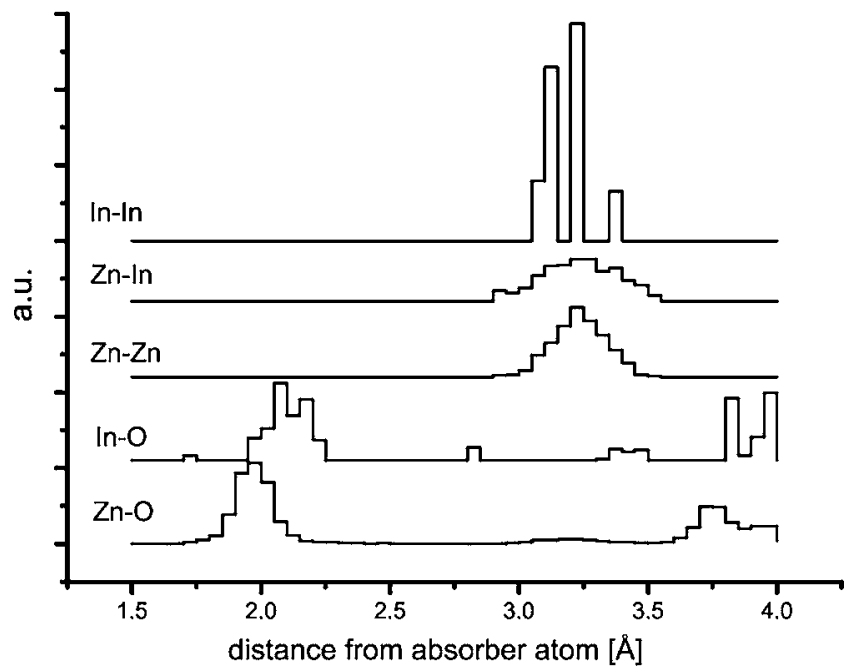

FIG. 12. Partial pair distribution function for $(5$ at. $\%)$ In-doped $\mathrm{ZnO}$ obtained by simultaneous RMC analysis of In- and Zn $K$ edge EXAFS spectra. with nearly constant values cannot be ruled out. Also for the $\mathrm{Zn}$-In distances there is good overlapping with VCA in contrast to In-O. Therefore, we propose that the deformation of the nearest neighbors around the In atoms does not extend to the next nearest neighbors. There has to be some kind of relaxation, for example, adjusting bond angles rather than bond distances, as In-O distances do not follow the VCA prediction. Our observations are in contrast to the results on other samples $\left[\mathrm{Zn}_{1-x} \mathrm{Mn}_{x} \mathrm{Se}\right.$ and $\mathrm{Cd}_{1-x} \mathrm{Mn}_{x} \mathrm{Te}$ (Ref. 25)] where nearly constant cation-anion and cation-cation distances are found covering large compositional ranges. The VCA-like behavior of $\mathrm{In}^{3+}$ in $\mathrm{ZnO}$ is related to the oxygen in the samples investigated here, with much higher electronegativity in comparison with higher chalcogenides. Therefore, the bonds are more ionic and the cation-anion distances in $\mathrm{ZnO}$ react much more sensitive on doping than $\mathrm{ZnSe}$ or CdTe. This is due to the fact that the charge density at $\mathrm{Mn}^{2+}$ in $\mathrm{ZnSe}$ is lower in comparison with $\mathrm{In}^{3+}$ in $\mathrm{ZnO}$.

A variety of initial configurations (with In on four- and sixfold interstitial sites) was used in the RMC analysis to verify the substitution of $\mathrm{Zn}$ by $\mathrm{In}$. The four- and sixfold positions are the only available interstitial sites. ${ }^{26}$ The resulting $R$ values were $\sim 1000 \%$ for fourfold interstitials and $50 \%$ for sixfold interstitials. Therefore, it is concluded that these models are unlikely for our samples. Another possible scenario is the formation of a separate $\operatorname{In}_{2} \mathrm{O}_{3}$ phase. This seems rather unlikely since there is no indication in XRD for a second phase in the sample and the observed change of the lattice parameters according to Vegard's law. Nevertheless, due to the small amount of In it might not show in XRD. Therefore, a corresponding model was run as RMC fit. Results of Rietveld refinements of pure $\operatorname{In}_{2} \mathrm{O}_{3}$ were used for the initial configuration of the second phase. The $R$ values were $16 \%$ and $60 \%$ for $\mathrm{Zn} K$ edge and In $K$ edge, respectively. It is obvious that this fit is worse compared to the model for In on $\mathrm{Zn}$ sites. Therefore, based on all results of XRD, EXAFS, VCA, and bond valence calculations it is concluded that In is located on substitutional $\mathrm{Zn}$ lattice sites and not on interstitial positions or as a separate phase of $\operatorname{In}_{2} \mathrm{O}_{3}$. These conclusions are in agreement with the results for nanocrystalline samples published in. Ref. 27.

The coordination number of oxygen neighbors for $\mathrm{Zn}$ is 3.0 (1.1) up to a distance of $2.3 \AA$ which is just below the value for the distance in the $c$ direction. This agrees well with the results from the Rietveld analysis, indicating a splitting of $\mathrm{Zn}-\mathrm{O}$ bond lengths; nevertheless they were not conclusive since the In-O distances are also contained in the information from XRD. ${ }^{17}$ RMC analysis with high resolutions of $0.01 \AA$ showed even stronger indications for the splitting of bond lengths as can be seen in Fig. 14 for an undoped $\mathrm{ZnO}$ sample.

The fits of the EXAFS spectra of Ga-doped samples were performed as described above. For Ga-doped $\mathrm{ZnO}$ samples the analysis is more complicated as the atomic numbers of $\mathrm{Zn}$ and $\mathrm{Ga}$ differ by only 1, resulting in a distance between $K$ edges of $\Delta E \sim 700 \mathrm{eV}$. Consequently, only the $Z n-K$-edge EXAFS data could be used from which only backscattering information on $\mathrm{Ga}$ is available. An $R$ value of $11 \%$ for the Zn $K$ edge was obtained for the assumption of 
TABLE V. Coordination numbers, coordination distances, and second moments for In-doped $\mathrm{ZnO}$ determined by moment analysis of partial pair distribution functions determined by RMC analysis of EXAFS spectra.

\begin{tabular}{lccccc}
\hline \hline Sample & $\begin{array}{c}\text { Absorber/ } \\
\text { scatterer pair }\end{array}$ & $\begin{array}{c}\text { Coordination } \\
\text { number } N\end{array}$ & $\begin{array}{c}\text { Distance } \\
r(\AA)\end{array}$ & $\begin{array}{c}\text { Second moment } \\
\sigma^{2}\left(\AA^{2}\right)\end{array}$ & Edge measured \\
\hline ZnO:In & $\mathrm{Zn}-\mathrm{O}$ & $3.9(5)$ & $1.98(2)$ & $0.007(2)$ & $\mathrm{Zn} K+\mathrm{In} K$ \\
ZnO:In & $\mathrm{In}-\mathrm{O}$ & $4.0(4)$ & $2.11(1)$ & $0.005(2)$ & $\mathrm{Zn} K+\mathrm{In} K$ \\
$\mathrm{ZnO}: \mathrm{In}$ & $\mathrm{Zn}-\mathrm{Zn}$ & $10.9(10)$ & $3.23(1)$ & $0.012(2)$ & $\mathrm{Zn} K+\mathrm{In} K$ \\
ZnO:In & $\mathrm{Zn}-\mathrm{In}$ & $1.1(17)$ & $3.24(1)$ & $0.023(2)$ & $\mathrm{Zn} K+\mathrm{In} K$ \\
ZnO:In & $\mathrm{In}-\mathrm{In}$ & $0.9(6)$ & $3.21(5)$ & $0.004(3)$ & $\mathrm{Zn} K+\mathrm{In} K$ \\
ZnO:Ga & $\mathrm{Zn}-\mathrm{O}$ & $3.9(5)$ & $1.98(1)$ & $0.007(2)$ & $\mathrm{Zn} K$ \\
ZnO:Ga & $\mathrm{Zn}-\mathrm{Zn}$ & $11.8(16)$ & $3.24(1)$ & $0.005(1)$ & $\mathrm{Zn} K$ \\
ZnO:Ga & $\mathrm{Zn}-\mathrm{Ga}$ & $0.2(2)$ & $1.98(1)$ & $0.003(1)$ & $\mathrm{Zn} K$ \\
ZnO:Al & $\mathrm{Zn}-\mathrm{O}$ & $4.0(8)$ & $1.98(2)$ & $0.008(4)$ & $\mathrm{Zn} K$ \\
$\mathrm{ZnO}: \mathrm{Al}$ & $\mathrm{Zn}-\mathrm{Zn}$ & $11.9(23)$ & $3.23(1)$ & $0.014(5)$ & $\mathrm{Zn} K$ \\
ZnO:Al & $\mathrm{Zn}-\mathrm{Al}$ & $0.2(3)$ & $1.93(5)$ & $0.038(13)$ & $\mathrm{Zn} K$ \\
\hline \hline
\end{tabular}

substitutional Ga. For a model with interstitial Ga atoms a value of $10 \%$ could be achieved. For a fit without any Ga atoms an $R$ value of $13 \%$ was achieved. Significant difference between the substitutional and interstitial models is not observed and no conclusion on the location of dopants is possible. In contrast to $\mathrm{Al}$ doping the backscattering information of $\mathrm{Ga}$ atoms is less conclusive because of the close vicinity of $\mathrm{Zn}$ and $\mathrm{Ga}$ in the periodic system. Therefore, the
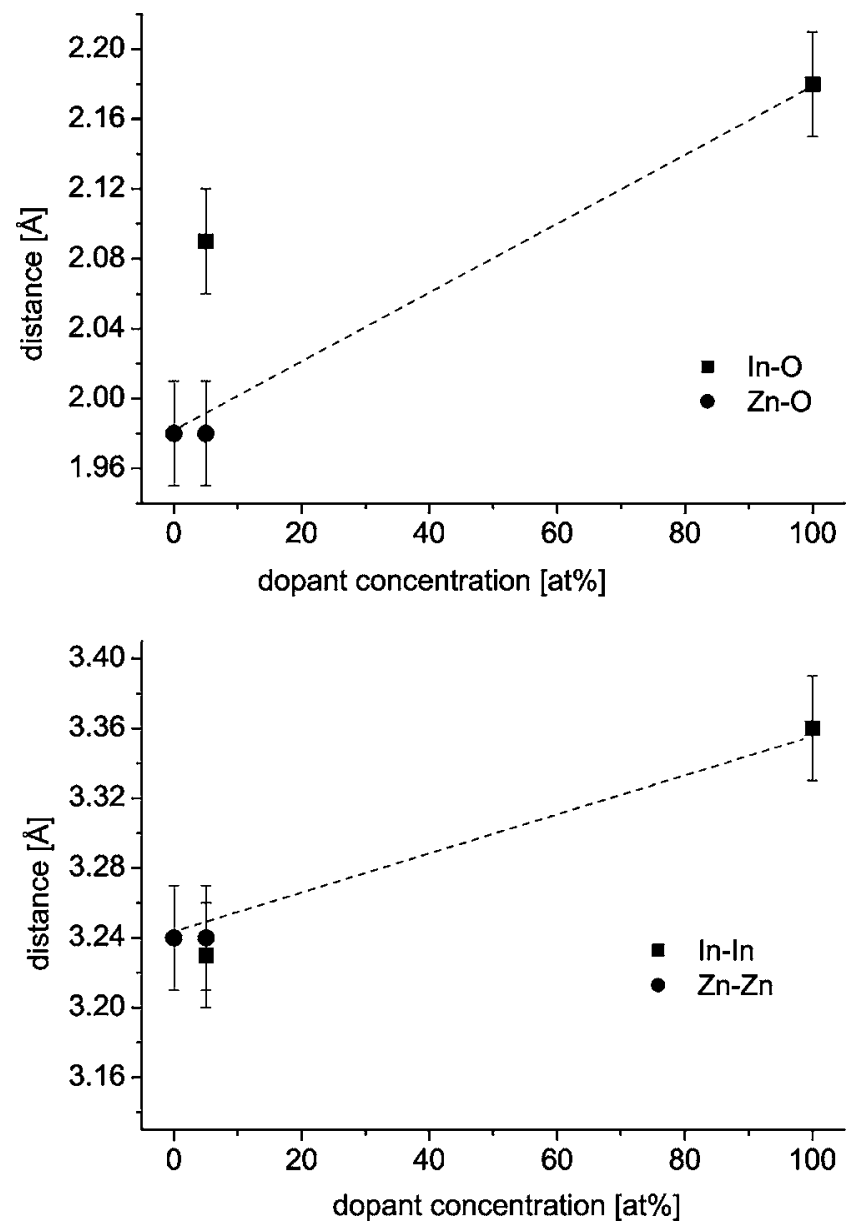

FIG. 13. Cation-anion (top) and cation-cation (bottom) distances for Indoped samples according to EXAFS/RMC results. The dashed lines are calculated from Rietveld results and indicate the behavior suggested by VCA. backscattering amplitudes and phase functions of the two elements are very similar. The RMC results hint that Ga ions reside on interstitial sites.

For the $\mathrm{Al}$-doped samples no $\mathrm{Al}-K$-edge data were available because of the low energy of the $\mathrm{Al} K$ absorption edge. Therefore, only backscattering information for $\mathrm{Al}$ in $\mathrm{Zn} \mathrm{EX-}$ AFS experiments is accessible. Good fits with and without $\mathrm{Al}$ atoms could be obtained (an $R$ value of $14 \%$ with $\mathrm{Al}$ on $\mathrm{Zn}$ sites and an $R$ value of $15 \%$ without $\mathrm{Al}$ ). In the pair distribution function of the model with substitutional $\mathrm{Al} \mathrm{a}$ splitting of the first $\mathrm{Al}$ peak is observed. This is an indication for Al located not on substitutional but interstitial sites. For $\mathrm{Al}$ on sixfold and fourfold interstitial sites $R$ values of $13 \%$ and $17 \%$, respectively, resulted after convergence. From these results it seems as if $\mathrm{Al}$ resides on the sixfold interstitial site. A separate phase is unlikely, since the change of lattice constants in $\mathrm{ZnO}$ suggests an incorporation of dopant atoms and no indication of an aluminum oxide is found in XRD. A sketch of four- and sixfold interstitial sites in the wurtzite structure is shown in Fig. 15. The radius ratio rule ${ }^{28}$ states that certain coordination numbers of anions around a cation are observed when the ratio of the ionic radii of cation to anion is larger than an empirically determined value. The minimum value of the radius ratio for octahedrally coordinated (interstitial) dopant ions in wurtzite is 0.414 (note that

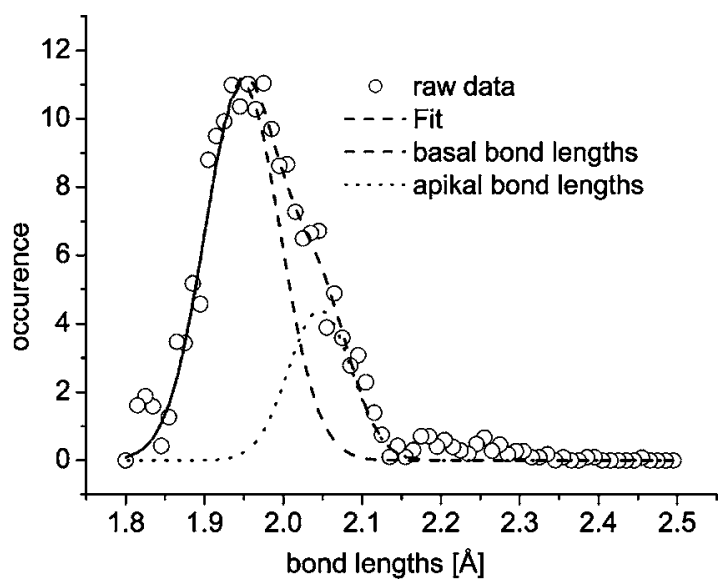

FIG. 14. Fit of bond lengths of pair distribution function of $\mathrm{Zn}-\mathrm{O}$ bonds with a resolution of $0.01 \AA$. 


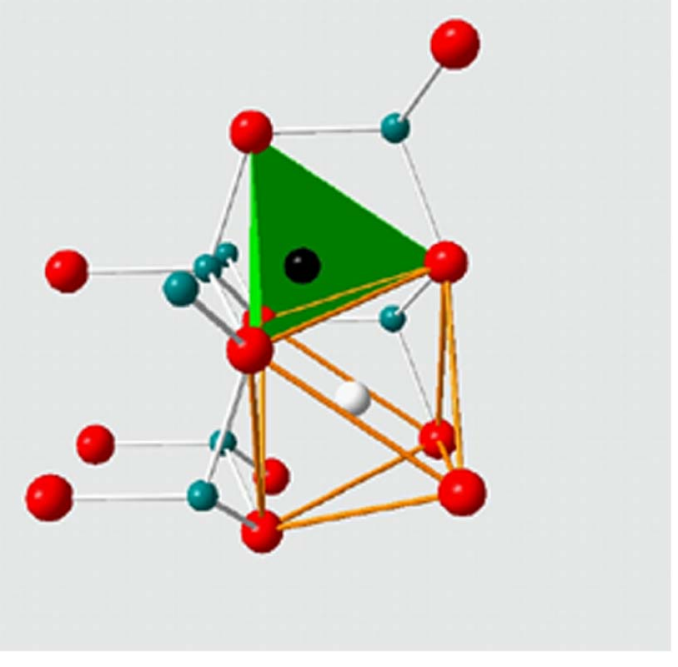

FIG. 15. (Color online) sixfold interstitial site (white) and fourfold interstitial site (black) in the wurtzite $\mathrm{ZnO}$ structure. The large spheres represent $\mathrm{O}$ atoms, while light gray spheres represent $\mathrm{Zn}$ atoms.

for tetrahedral coordination the minimum value is 0.225 ); therefore, the sixfold coordination is possible for $\mathrm{Al}$ in this structure.

Together with the results from XRD presented in Table IV a difference for sixfold coordinated $\mathrm{Al}$ and $\mathrm{Ga}$ can be seen; the bond distances parallel to the hexagonal plane decrease slightly for these dopants whereas the bond distances in the $z$ direction increase, reflecting again the possibly larger internal pressure or microstrain in the particles. Also a selective concentration at the surface as described in Ref. 29 could be explained; nevertheless this kind of concentration gradient is usually not observed in powders synthesized by CVS. The larger strain in the particles with higher dopant concentrations is also due to the smaller grain size (see Ref. 30 for grain size dependent strain results in undoped $\mathrm{ZnO}$ ).

\section{SUMMARY AND CONCLUSIONS}

Nanocrystalline $\mathrm{ZnO}$ powders were produced by atmospheric pressure CVS. The grain size depends on type and amount of doped group III atoms. Only In- and Ga-doped samples followed Vegard's law. Al-doped samples behave significantly different. In atoms clearly reside substitutionally on $\mathrm{Zn}$ lattice sites. They show a larger distance to their next oxygen neighbors compared to $\mathrm{Zn}$ atoms, but the value is significantly lower than in pure indium oxide. This can be understood by the larger ionic radius and the higher charge density of In atoms in comparison with $\mathrm{Zn}$. Due to an increase of the parameter $u$ an increase of one $\mathrm{Zn}-\mathrm{O}$ bond is observed by XRD and verified by EXAFS. The In atoms also exhibit a fourfold oxygen coordination just like the zinc atoms. The results suggest that Ga resides on interstitial sites like Al. The local structure around $\mathrm{Ga}$ atoms seems to be more distorted compared to the In-doped samples. The anomalous change of lattice parameters for Al-doped samples can be understood using the parameter $u$ obtained by Rietveld analysis. The parameter $u$ representing the relative position of the anion sublattice is much larger than for the other dopants. Increasing $u$ means a softer $\mathrm{Zn}-\mathrm{O}$ bond along the $c$-axis direction. Therefore, a large decrease of the lattice parameter $c$ is observed. The local structure around dopant atoms by EXAFS measurements with subsequent RMC analysis indicates a sixfold coordination of $\mathrm{Al}$ atoms. Future work will be done on NMR analysis of Al-doped samples.

\section{ACKNOWLEDGMENTS}

The authors gratefully acknowledge the financial support by the Federal Ministry of Education and Research (BMBF) through Project No. 03N4018. The XAFS measurements have been performed at the HASYLAB at DESY in Hamburg. The authors thank the staff of the A1 and X1 beamlines, particularly Edmund Welter, for their help.

${ }^{1}$ K. Badeker, Ann. Phys. 22, 749 (1907).

${ }^{2}$ H. L. Hartnagel, A. L. Dawar, A. K. Jain, and C. Jagadish, Semiconducting Transparent Thin Films (IOP, London, 1995).

${ }^{3}$ S. Klein, M. Winterer, and H. Hahn, Chem. Vap. Deposition 4, 143 (1998).

${ }^{4}$ K. Ellmer, J. Phys. D 34, 3097 (2001).

${ }^{5}$ F. Decremps, F. Datchi, A. M. Saitta, J. P. Itié, A. Polian, F. Baudelet, and S. Pascarelli, High Press. Res. 22, 365 (2002).

${ }^{6}$ M. S. Tokumoto, S. H. Pulcinelli, C. V. Santilli, and V. Briois, J. Phys. Chem. B 107, 568 (2003).

${ }^{7}$ E. M. Bachari, G. Baud, S. Ben Amor, and M. Jacquet, Thin Solid Films 348, 165 (1999).

${ }^{8}$ C. Kiener, M. Kurtz, H. Wilmer, C. Hoffmann, H. W. Schmidt, J.-D. Grunwaldt, M. Muhler, and F. Schüth, J. Catal. 216, 110 (2003).

${ }^{9}$ R. M. Friedman, J. J. Freeman, P. A. Berger, and F. W. Lytle, Bull. Am. Phys. Soc. 22, 319 (1977).

${ }^{10}$ G. Vlaic, J. C. J. Bart, W. Cavigiolo, N. Pianzolo, and S. Mobilio, J. Catal. 96, 314 (1985).

${ }^{11}$ T. Moriga, A. Fukushima, Y. Tominari, S. Hosokawa, I. Nakabayashi, and K. Tominaga, J. Synchrotron Radiat. 8, 785 (2001).

${ }^{12}$ M. S. Tokumoto, A. Smith, C. V. Santilli, S. H. Pulcinelli, E. Elkaim, and V. Briois, J. Non-Cryst. Solids 273, 302 (2000).

${ }^{13}$ J. Rodriguez-Carvajal, FULLPROF, 2001.

${ }^{14}$ J. Albertsson, S. C. Abrahams, and A. Kvick, Acta Crystallogr., Sect. B: Struct. Sci. 39, 408 (1983).

${ }^{15}$ M. Winterer, J. Appl. Phys. 88, 5635 (2000).

${ }^{16}$ S. I. Zabinsky, J. J. Rehr, A. Ankudinov, R. C. Albers, and M. J. Eller, Phys. Rev. B 52, 2995 (1995).

${ }^{17}$ M. Winterer, Nanocrystalline Ceramics (Springer, Berlin, 2002).

${ }^{18}$ V. Perebeinos, S.-W. Chan, and F. Zhang, Solid State Commun. 123, 295 (2002).

${ }^{19}$ P. Ayyub, V. R. Palkar, S. Chattopadhyay, and M. Multani, Phys. Rev. B 51, 6135 (1995)

${ }^{20}$ E. H. Kisi and M. E. Elcombe, Acta Crystallogr., Sect. C: Cryst. Struct. Commun. C45, 1867 (1989).

${ }^{21}$ O. Garcia-Martinez, R. M. Vojas, E. Vila, and J. J. Martin de Vidales, Solid State Ionics 63-65, 442 (1993).

${ }^{22}$ S. Desgreniers, Phys. Rev. B 58, 14102 (1998).

${ }^{23}$ C. Hormillosa and I. D. Brown, BOND valence CALCULATOR software, McMaster University, 1993.

${ }^{24}$ L. Galoisy, Phys. Chem. Miner. 23, 217 (1996).

${ }^{25}$ W. F. Pong, R. A. Mayanovic, B. A. Bunker, J. K. Furdyna, and U. Debska, Phys. Rev. B 41, 8440 (1990).

${ }^{26}$ W. D. Kingery, H. K. Bowen, and D. R. Uhlmann, Introduction to Ceramics (Wiley, New York, 1975).

${ }^{27}$ T. Agne, Z. Guan, X. M. Li, H. Wolf, T. Wichert, H. Natter, and R. Hempelmann, Appl. Phys. Lett. 83, 1204 (2003).

${ }^{28}$ A. R. West, Basic Solid State Chemistry, 2nd ed. (Wiley, New York, 1999).

${ }^{29}$ M. Shim, C. Wang, D. J. Norris, and P. Guyot-Sionnest, MRS Bull. 26, 1005 (2001)

${ }^{30}$ V. Ischenko, S. Polarz, D. Grote, V. Stavarache, K. Fink, and M. Driess, Adv. Funct. Mater. 15, 1945 (2005) 